THURSDAY, APRIL 22, 1880

\section{THE ST. GOTHARD TUNNEL}

$7 \mathrm{HE}$ news that the two advance borings had met in 1 the middle of the mountain traversed by the St. Gothard tunnel resounded like a joyful echo in every civilised country. It announced the success of the greatest work hitherto attempted by man; and, on the completion of so important an event, the scientific public must with good reason insist on having some details of the gigantic labours which have excited the attention of all intelligent men, and which, though well nigh finished, still demand much skill and energy.

The St. Gothard Tunnel is intended to form part of the railway connecting the North Sea with the Mediterranean; the ports of Belgium, Folland, and Germany with Genoa; the Rhine basin with that of the Po, by passing through the chain of the Alps at its most central point. If this point has been chosen in preference to any other, it is because the line through St. Gothard is the most direct. A proof that the passage is well selected is that, if one compares all the roads crossing the Swiss Alps, he will find that the St. Gothard one is more frequented by travellers either walking or riding than all the others together.

If, therefore, the Mont Cenis railway preceded that of St. Gothard, it is because there were political reasons for its accomplishment; it is because science had not yet discovered the means of boring, in a relatively short time, long tunnels without shafts. But the experiments made in Mont Cenis being conclusive, the governments, cities, companies, and private persons who were interested all set to work, and the great international line subsidised by Italy, Germany, and most of the Swiss cantons was commenced in real earnest.

Before the Company was formed, a most thorough inspection was made on the spot, and the engineers concluded that the great inevitable tunnel could have its openings only near the small village, Goeschenen (Canton Uri), on the north, and near Airolo (Canton Tessin) on the south. Goeschenen is I, 109 metres above sea-level, and 672 above the Lake of the Four Cantons. Airolo is $\mathrm{r}, 145$ above the sea. Considerable works, therefore, are necessary to reach so great elevations by means of a railway. But to lower the level of the tunnel by only a few metres while awkwardly increasing the length, and to ascend higher to lessen that length, only alleviated the difficulty to a trifing extent, especially on the south slope, where Airolo is almost the only possible point of entrance.

Both openings being thus decided upon, the first thing to do was to lay down the plan of the tunnel and ascertain its direction and level. Thanks to the excellent topographical map possessed by Switzerland, it was evident, even without examination made on the spot, that the tunnel might be straight, and that its length would be about 15,000 metres. Afterwards it was thought preferable to complete it at the southern end by a slight curve, to give more facilities for building the Airolo station, but the tunnel throughout was opened in a straight line, and it was not till later that a curved bifurcation of 125 metres was made near the mouth.

Vor. $\mathrm{xxI},-\mathrm{No} .547$
In St. Gothard there were not the same topographical advantages as in Mont Cenis. In the operations made to trace the tunnel under the latter, there was at the highest part of the ground a starting-point from which could be seen, if not the two openings, at least points in their neighbourhood placed on the continuation of the very axis of the tunnel. They were able accordingly to build at a high elevation an observatory supplied with a field-glass rotating in a vertical plane passing through the middle of the tunnel. From that observatory two other observatories were determined in the same vertical plane towards the mouths of the tunnel, and the field-glasses of the two new observatories very easily supplied, when necessary, the direction of the tunnel axis.

On St. Gothard it was entirely different. The mountain presents several ridges over the tunnel. At no point can the places near both openings be seen at once, and some of the summits are so steep and bigh that it is impossible to take observations, and any direct tracing of the line over the mountain is impracticable. It was therefore necessary to make an indirect tracing, that is, to connect the extremities of the line of direction by means of a chain of triangles, calculate the relative posi tion of the two openings, and thence deduce the angle formed by the tunnel axis either with the sides of the triangles of which Goeschenen and Airolo are the ver. tices, or with the meridian. This operation was facilitated by the great triangulation of the map of Switzerland, five vertical points of which are near the tunnel and could be utilised, but only as checks, since the entire work was done afresh, and it was even necessary to reconstruct the points of observation, many having disappeared, and nearly all of them being on peaks placed above the perpetual snow-level. M. Gelpke, the engineer who had charge of the triangulation, measured a base line of $1,45^{\circ}$ metres in the Urseren Valley, and then measured all the angles not only of the eleven triangles comnecting the two mouths, but also of several triangles used for veritication. It was necessary to work with extreme care, as a mistake in direction of only five seconds would produce a deviation of 40 centimetres in the middle of the tunnel. Besides the verification indicated, another was made by a system of arrows continued from the point where the tunnel-axis was calculated to interscct the observer's base line in the direction of the line forming with the base the angle given by calculation. This measurement by arrows was continued as far as Goeschenen, and led precisely to the mouth of the tunnel.

When measuring the angles of the triangles, M. Gelpke also took the vertical angles, and was able to calculate the difference in altitude of the tunnel-mouths. The level moreover was ascertained directly, and connected with the great European triangulation of precision, which passes directly over the Col of St. Gothard.

The direction and level having been thus obtained, observatories were placed near the tunnel-mouths, to serve as direction-points for the miners. At Airolo there was no difficulty in fixing the observatory, the site being suitable; but at Goeschenen, where the direction of the tunnel forms with the narrow and deep valley a very acute angle, there was not a sufficient line of sight, and it was necessary, in order to have one, to traverse two C C 
projecting rocks with two small bores 1 I 5 and 93 metres long, and only then could observations satisfactorily be made either as to direction or level.

In each observatory was placed a large theodolite, and after a very large number of angular measurements and astronomical verifications, arrows and levelling-marks were placed in the exact direction of the tunnel, so that at every moment during the first stage of the tunnelling works the direction in which the miners were advancing could be verified.

In spite of the success of the verifications of M. Gelphe's labours, the managers of the St. Gothard Company thought it right to recommence the triangulation in 1874 , employing another engineer, M. Koppe, and a different system. Instead of limiting himself to summits in the neighbourhood, and having moderately-sized triangles

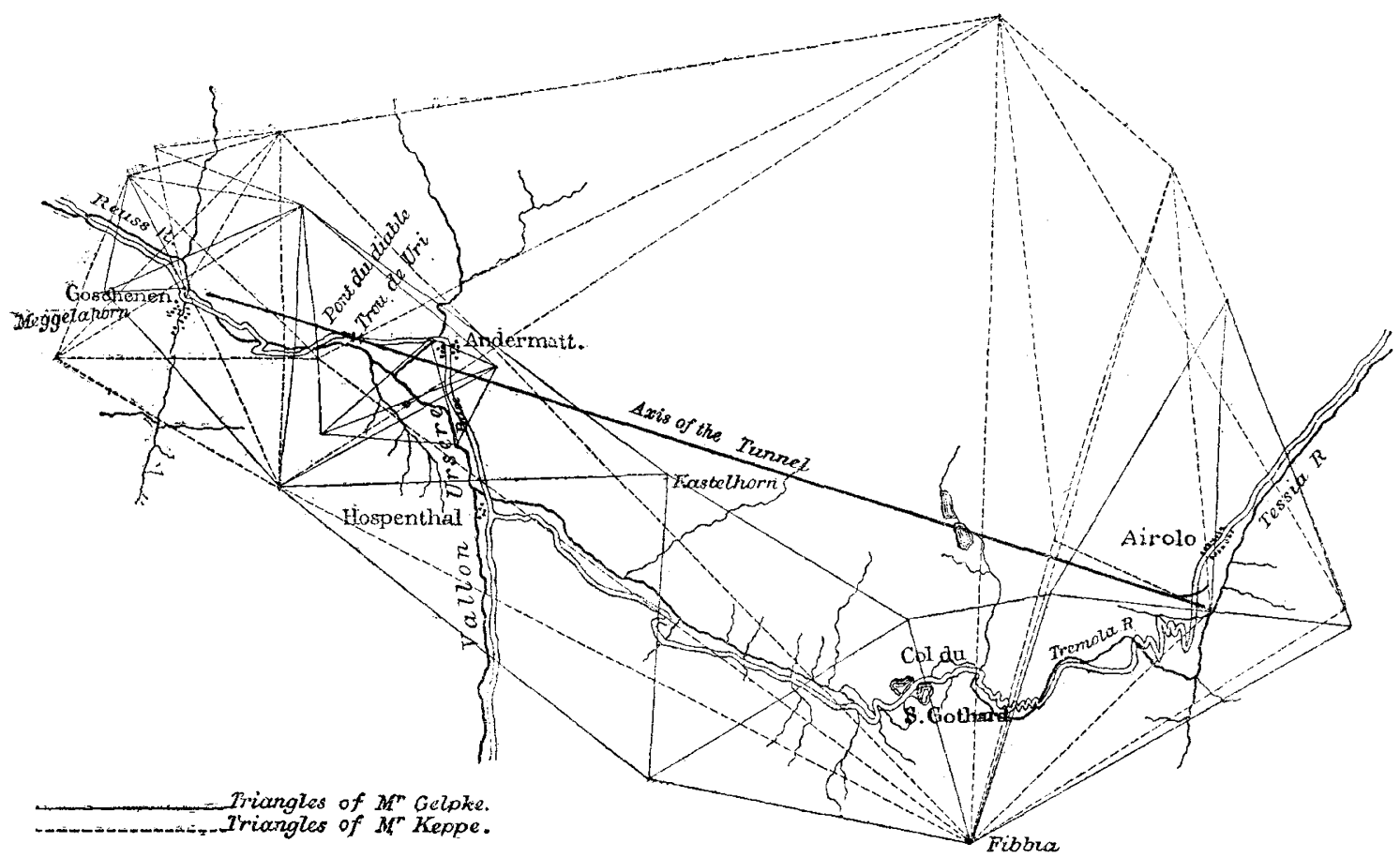

FIG، I. - Plan of Triangulation for the St. Gothard Tunnel, Is

(the longest side being under 7,000 m.), M. Koppe preferred to use as large triangles as possible, in order to connect together by a minimum number of intermediary stations the two tumnel openings. No doubt, since these openings are at the bottom of valleys, a certain number of triangles was necessary to descend from the heights; but the sides of triangles of from ro to 15 kilometres connect directly the signals on the heights above Goeschenen with those of the heights near Airolo, and several triangles for the purpose of verification were laid down. The two operations proving the accuracy of the works were ( $I$ ) the correspondence within two seconds of M. Koppe's triangulation with that of M. Gelpke; (2) the following almost direct and very interesting verification. MI. Koppe started

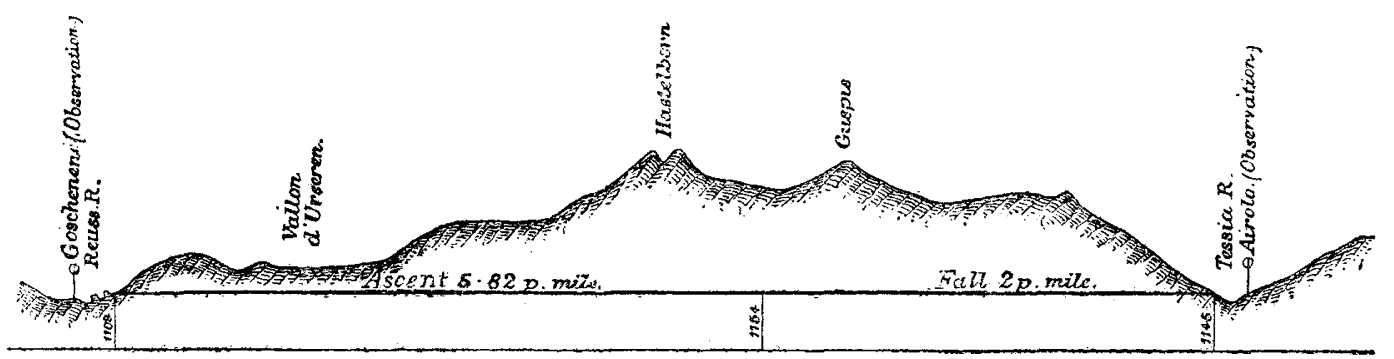

FIG. 2.-Profile along the length of the Tunnel.

a system of arrows from Airolo northwards along the axis the tunnel-axis. He thus ascended the flanks of a mounof the tunnel over the mountain, following the direction given by the observatory to the highest attainable point near Kastelhorn, where he erected a mast. Being unable to reach this point from Goeschenen by going south, on account of the local difficulties, he started northwards also from that opening, in the direction of the continuation of tain till he could observe in the distance the mast he had erected near Kastelhorn. Then observing the level of Goeschenen with a theodolite, he moved his field-glass in a vertical plane, and directing it upon Goeschenen, he was delighted to see his mast almost in the centre of his field of vision, at a distance from his estimated axis of 
about 15 centimetres. It might therefore be assumed that that axis traced in air is of great accuracy.

As to the operations for verifying the direction within the tunnel, they are in theory very simple. So long as the boring was not far advanced it was given directly by the direction-points by means of field-glasses fixed in the observatories. At Goeschenen this was done till they had bored to a depth of I, 300 metres, but at Airolo the atmosphere was saturated with vapours, and thus they could

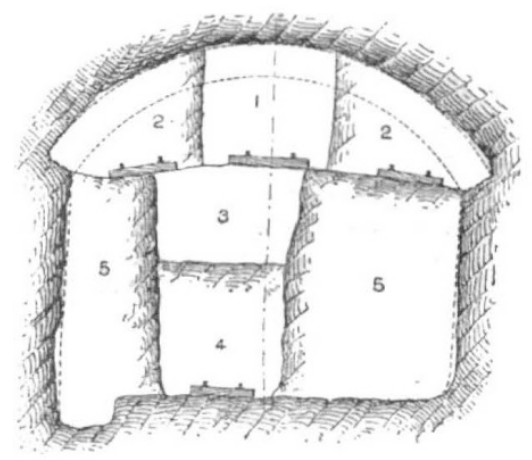

FIG. 3,-System of excavation, $\frac{1}{80}$. I, Advance Gallery : 2, Side workings ; 3, 4, "Cunette de Strosse"; 5, "Strosse."

not advance more than $600 \mathrm{~m}$. Beyond those limits, therefore, it was necessary to have several stations. By means of the observatory, lamps were fixed in the exact direction of the axis. Then, a theodolite being placed behind the lamps in a line with them, its telescope was reversed, and the direction thus determined from the bottom of the boring. Lamps were then placed in this line of direction on hooks fastened to the roof of the tunnel.
They could thus advance and increase the numbers of observing stations as they found necessary, either from the increased length of the boring or the want of transparency in the air. This operation, apparently very simple, is in reality very long and complicated, and to effect it various instruments were made use of which were improved during the works. As to the lamps, after trying different modes of lighting, they came back to ordinary petroleum lamps with round wicks, which were placed on stands carefully hung up and centred, and on which the instrument was then placed. To effect communication between the different stations of the instrument and lamps, experience soon proved that the simplest and most economical plan was to use a field telegraph, which was lengthened as they advanced.

Direction-points were given to the contractor every 200 metres, and they were fixed by producing the direction of the preceding points of reference. Twice or thrice a year, however, the operation of tracing the direction from the observatories was recommenced, as if that work had never previously been done; only when passing under each hook which had been fixed in the previous operations they compared the new result with the preceding, and thus ascertained the changes of direction. In the northern boring the greatest deviation was two centimetres, and that of the south, owing to the vapours, seven.

The result of that operation was a tunnel 14,920 metres long, starting on the north at the level $\mathrm{I}, 109$, rising at the rate of 5.82 in a thousand to the level 1,152 , which was attained about the middle of the tunnel, and a small level being left in case of any possible error in levelling, it fell at the rate of 2 in a thousand to the level 1,145 at the Airolo station.

Having thus indicated how the direction of the tunnel

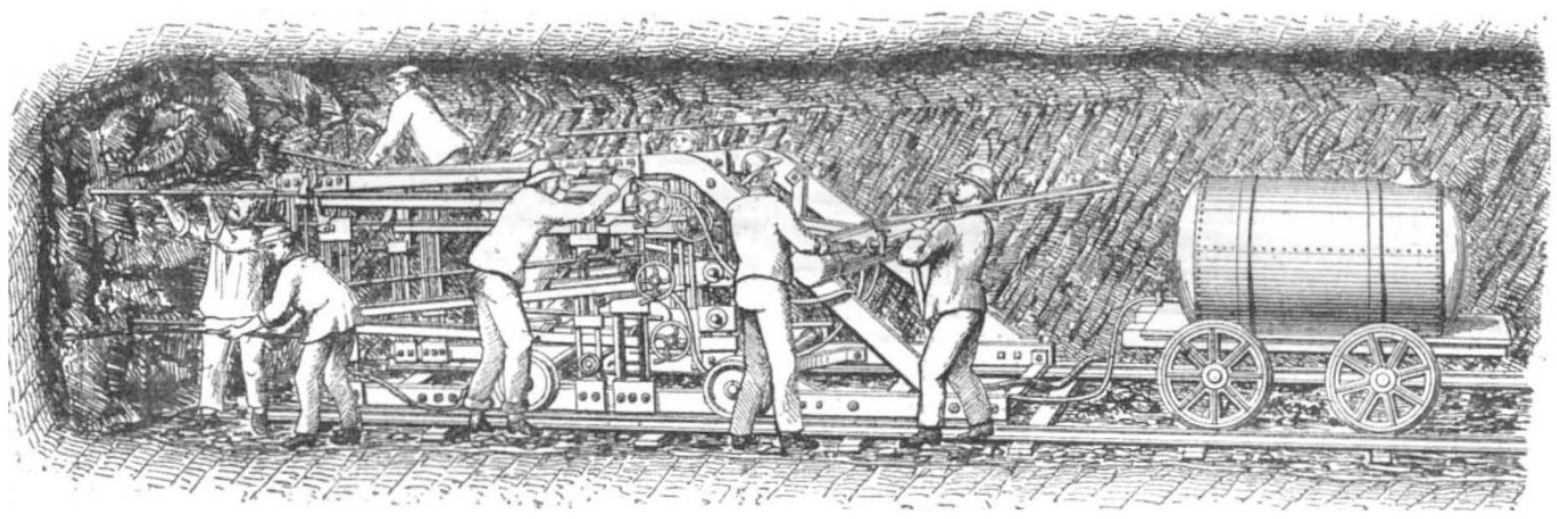

FIG. 4.-The borers at work.

was traced, let us examine the procedure employed in the works properly so called.

After the experiment made in Mont Cenis, they had only to follow it and at the same time take advantage of the improvements since made on the system; the two principles without which the work would have been impossible being mechanical perforation of mine-holes and the transmission of force by compressed air.

Without the English invention of machines for boring rocks, the opening of a long tunnel without shafts or external openings would have occupied so long a time that no company could undertake it. But, thanks to the experiments made elsewhere, M. Louis Favre, the contractor of the tunnel, was able to utilise those excellent boring machines which have powerfully assisted in hastening the work. His object was constantly in the direction of suppressing hand-boring, and he almost attained it by making use of several models of machines which cannot be described here, but which are distinguished by the names of their inventors, Dubois and 
Francois, Ferroux, Mackean, and Turrettini. All these machines have one common object, to project forcibly, and with blows of the greatest rapidity, a tool against the rock, and, as it is drawn back, force it to rotate slightly on its axis. Some of the machines advance by an automatic movement; others require a workman to push them. But to keep these boring machines in action some considerable motive power is necessary, and in the Alps that motive power can only be water. The question, then, is How to collect it and transmit it into the tunnel?

Close by the Goeschenen opening runs the River Reuss, which has just passed under the legendary "Devil's Bridge," and precipitates itself into its narrow and rocky bed with an average fall of 10 per I00, forming a volume of water which is never less than I,000 litres per second. M. L. Favre utilised a large rock standing in the channel to fix his dam, below which the water is received in a reservoir to deposit its sand and gravel. Thence it is led to the machines by a cast-iron pipe $85 \mathrm{~m}$. in diameter and $800 \mathrm{~m}$. long. The useful fall from the pipe is $85 \mathrm{~m}$, and it can supply 1,200 litres a second. This water works four Girard wheels with horizontal axes. Their diameter is 2.4 ; they revolve 160 times a minute, and are each of 250 to 280 horse-power. When turning a horizontal axis with cranks and wheels attached, the number of revolutions is reduced to 80 per minute.

At Airolo, the nearest river being the Ticino, which has no rapid descent, it would have required a very long canal to procure enough of fall. M. Favre therefore followed the advice of engineers who had studied the matter and assured him he would find enough water by making use of the Tremola, a torrent close by the tunnel, which falls into the valley with an average descent of 20 per 100 , and is said to supply at least from 300 to 400 litres a second at the bottom. By collecting the water at a height sufficient to allow of the receiving reservoir giving a useful fall of I $80 \mathrm{~m}$., the necessary motive power could thus be found. The works were completed in 1872 , but in February, 1873, the supply of the Tremola fell to Ioo litres, and there was not sufficient power to turn the waterwheels. This did not last long, it is true, but the same scarcity of water reappearing next year, M. Favre resolved to form an auxiliary supply by collecting the Ticino water 3 kilometres up the river, and thus have a new fall in order to meet all eventualities. By this means four tangential water-wheels with vertical axes are turned; they are of bronze, with a diameter of $\mathrm{I} \cdot 2 \mathrm{~m}$., and revolve' 350 times a minute, each being of about 200 horse-power. By means of conical gearing they turn a horizontal axis with cranks revolving 85 times a minute. When the supply of the Ticino is insufficient, it is made to act on a smaller number of wheels; and then on the vertical axles, which are no longer turned by that stream, there are other water-wheels slightly different on which the water of the Ticino is brought to bear.

The power communicated to the horizontal axis at each opening is transmitted into the tunnel by means of the remarkable system already employed at Mont Cenis, and the inventor of which is Prof. Colladon of Geneva. This engineer conceived the idea of using for that purpose compressed air. The immense advantage gained by it is the transmission of a motive power, whatever the tem- perature or distance may be ; moreover, it serves for ventilation and the supply of fresh air.

But the compression of air develops great heat, which injures the machine. At Mont Cenis, to avoid this heating, the air was compressed by means of pistons of cold water, which were themselves pushed by ordinary pistons moving up and down in pump cylinders. In order that the piston pushing the water should move it without splashing it must itself be moved very slowly, and the quantity of air required being considerable, the slowness of the movement must be compensated by the size of the pumps. At St. Gothard the following new invention of M. Colladon was utilised to prevent the temperature from becoming too high. The body of the compression-pump is double, and between its outer and inner cylinder circulates a current of cold water introduced by pumps. This cold water also circulates in the hollow rod of the piston and in the piston itself, which is also hollow. Moreover, cold water under the form of fine dust is injected even into the interior of the body of the pump, and then expelled by each stroke of the piston along with the compressed air. In this manner air compressed at 8 atmospheres only assumes a temperature of $32^{\circ} \mathrm{C}$., which is lowered in the reservoirs to which it is exposed before passing into the tunnel. By this ingenious arrangement we can give much more rapidity to the pistons and proportionately diminish the volume of the pumps.

At Airolo and Goeschenen there are fifteen such pumps, divided at each place into five groups of three. They are horizontal, and their pistons are set in motion by beams connected with the cranks of the main axis. They serve a double purpose at the bottom of each pump cylinder there are two expiration valves and one for supply. The Airolo pumps are of $46 \mathrm{~m}$. interior diameter, and at each stroke of the piston (through $45 \mathrm{~m}$.) a pump receives $7 \mathrm{I}$ litres of air, and by compression reduces this volume to a seventh part. In this manner, when the supply is adequate ( 160 litres for each wheel), four groups of three pumps (one of the five groups being generally left at rest) receive in twenty-four hours 208,000 cubic metres of air, whereas the volume required is 104,000. At Goeschenen the pumps are of $42 \mathrm{~m}$. diameter, and at each stroke of the piston (through $65 \mathrm{~m}$.) 87 litres are received; but the number of strokes of the piston is rather less.

The compressed air is sent into reservoirs, where it is cooled, and the water in suspension deposited. Thence it is conducted by tubes into the tunnel. These conducting tubes are pipes of hammered iron of $20 \mathrm{~m}$. diameter, which are bolted together end to end, and placed all along the tunnel. At each new stage of the work the expenditure of air diminishes as they advance, and the diameter of the pipes is accordingly ieduced to 14 , then to 10 , till at last they terminate in india-rubber tubes of 5 centim., which supply the compressed air for working the advanced gallery.

The process being now known, let us examine how the work is organised. The tunnel being $8 \mathrm{~m}$. wide and $6 \mathrm{~m}$. high above the rails, since it must be vaulted, it is necessary to make a clearance as high as $6 \frac{1}{2} \mathrm{~m}$. above the rails. The first thing is to make a preliminary or advanced boring $2 \frac{1}{2} \mathrm{~m}$. high and $2 \frac{1}{2} \mathrm{~m}$. broad. For this first boring M. Favre adopted the Belgian system, according to which the preliminary gallery is entirely at 
the top of the tunnel. To open this boring, six perforating machines were arranged on a cast-iron stand placed on rails. These machines, first of all, perforated six holes in a horizortal direction. Then shifting the points, they macle six new holes, and again a third set and a fourth set. This ought to have produced twenty-four perforations; but as there was always some delay from the change of drills or other hindrances, they seldom had more than eighteen or twenty. As the tools striking on the rock became very hot, and much dust was produced in the holes, they required to be constantly moistened by a jet of water. The water was carried on a train behind the cast-iron stand, and, by means of an india-rubber pipe to convey compressed air, was projected forcibly in several jets.

The holes bored were generally I $\mathrm{m}$. deep. When the face of the rock was, in the opinion of the head miner, sufficiently perforated, the stand was drawn back and the holes were charged with a mixture of dynamite and clay. Then they were fired by means of slow matches, so arranged that the central holes should explode before the others. After that they broke the large fragments, loaded trucks with the rubbish, and rolled them towards the opening; and thus the gallery was advanced about $I \mathrm{~m}$. Then placing rails in front, the stand with its boring-machine was brought back, and the mining recommenced.

The advance was more or less difficult according to the nature of the rocks, but on the whole the contractor was fortunate in this respect. The rock was hard, but its hardness was almost always suitable for perforation. About three-quarters of an hour were necessary to make a hole I metre deep; and under favourable circumstances four operations would be made in twenty-four hours, that is to say, an advance of 4 metres on each side. The most favourable rocks were granite, gneiss, mica gneiss, and mica schist. The layers, which were almost vertical, lay from east to west, and were therefore at right angles to the direction of boring. There were, however, three unfavourable circumstances which greatly hindered the works at certain times:-(r) The infiltrations of water in the Airolo tunnel during the first months of the operations, and in such quantities that a regular river flowed from the southern opening. Fortunately dynamite is not affected by water, and after boring several hundred metres the infiltration stopped. (2) Rocks of exceptional hardness were met with from time to time blunting the best drills, and scarcely an advance of I metre a day could be made. (3) $I r$ the Goeschenen gallery, at $2,700 \mathrm{~m}$. from the mouth, they came upon a bed of rock entirely disaggregated, where they could only work with the pickaxe and were afraid of being buried. Under the enormous pressure of the mountain the props were crushed, and even the arches of masonry overthrown. At this part the advance was from 30 to $40 \mathrm{~m}$. a month, and it continued for more than four months. There was some danger even of the rock falling behind where the workmen were engaged, and so isolating them and all who were beyond. In order to strengthen this dangerous part it was necessary to employ a special system of arches strengthened with iron.

When the advanced boring was completed, it was enlarged on the right and left. After that was done, they proceeded to build the arches of the roof, and then dug to the level of the tunnel's base a trench of about $3 \mathrm{~m}$. wide, called the Cunette de Strosse. It is not dug in the middle, so as to leave as long as possible the way clear on the higher level. Then all is removed that remains on the right and left of the trench, and which is known as Strosse.

These different excavations are almost all done by perforations, and the holes being bored downwards, the work is more easy, whether for boring or exploding.

The transport of rubbish and materials had to be performed as often as possible by more powerful agents than manual power or horse-power. Steam-engines were out, of the question, the air being already vitiated by the constant percussion of the boring-drills. The compressed air was employed to move the locomotives, just as if they were acted upon by steam. It was collected in reservoirs placed on the locomotive trains, and by simply turning a cock the machine was moved or stopped. But as the air of the atmosphere did not furnish a "course" sufficient, except by means of enormous reservoirs, they constituted "compressors" of the same system as those already in use, but which compressed the air to fourteen atmospheres. With so considerable power the locomotives were sufficiently supplied by ordinary reservoirs.

Charge of the works was handed over to the contractor, M. Favre, in October, 1872 , on condition of completing them within eight years; should they occupy nine years, a heavy penalty was attached. On February 29, 1880, the two advanced borings met with great accuracy. By a mistake the general direction only was taken, and therefore the exact amount of error was not ascertained, but it could not have exceeded ro centimetres (or less than 4 inches)! This meeting did not take place in the middle of the tunnel, but at a point about $600 \mathrm{~m}$. nearer Airolo than Goeschenen. The newspapers fully reported the event, the joy of which was greatly mingled with sorrow on account of the death of Louis Favre, the energetic and intelligent contractor, who was to have presided at the ceremony, after having organised and directed all the details, and at the very moment when he was about to realise the aim of his efforts. $\mathrm{He}$ died suddenly in the tunnel, the offspring of his labours, on July 19, 1879 . Born in 1826 in Chène, near Geneva, he left his native place as a journeyman carpenter, and by his intelligence and talent returned to Switzerland thirty years afterwards to be intrusted with the greatest undertaking of the present time. As he had thoroughly well organised everything, the works were continued without him, and also completed; but when shall we find such another man to begin again such another undertaking?

There is still much to do in the tunnel-rocks to clear away, mason-work to be built, \&c.-but now the ground is known, and there is no fear of being able to complete the tunnel within the stipulated time. But what purpose would it serve? The lines of approach could only be finished long after the tunnel, being much less advanced. It is proposed, however, to have carriages running next winter between Goeschenen and Airolo, driven by atmospheric locomotives. That would no doubt be an advantage, but would the result be worth the great exertions necessary?

Much bas been said of the extreme heat which prevails in the tunnel, and there is no doubt it is almost intolerable, being $32^{\circ}$ to $35^{\circ} \mathrm{C}$., and is injurious to men, and 
especially to horses. But when the tunnel is entirely cleared out and there are no more dynamite explosions, a current of air will set in ; and as there are only 3 kilometres more than at Mont Cenis, there is no reason why, in respect of ventilation, it should be more dangerous.

We may therefore confidently utilise this magnificent way of communication, and be proud of living at the period during which it has been opened.

Geneva

ADOLPHE GaUtier, Engineer

\section{COLLOIDS}

The Infuence of Colloids upon Crystalline Form and Cohesion. By W. M. Ord, M.D. (London: Stanford, 1879.)

THE series of researches which Dr. Ord has put into the hands of the public in the volume before us possess a double value, as dealing with problems in molecular physics of the deepest intere $t$ to the physical investigator and of the highest importance to the surgical practitioner.

The starting-point of Dr. Ord's work is to be found in very remarkable research made more than twenty years ago by $\mathrm{Mr}$. George Rainey, on the spherical forms assumed by carbonate of lime and other crystalline substances when deposited in the midst of gummy or colloidal liquids. The process by which this assumption of a globular form is effected Mr. Rainey termed "molecular coalescence." He also assigned the name of "molecular disintegration" to another process by which the conditions are reversed, and which breaks up the spheres into forms possessing a structure more nearly approaching a crystalline character. The most important of his deductions was undoubtedly the conclusion that the rounded forms of organised bodies depended on physical and not on so-called vital conditions. If solutions of gum arabic (containing malate of lime) and concentrated carbonate of potash are placed together in a bottle with as little mixing of the two as possible, the most perfect microscopic spheres are slowly deposited. They exhibit both concentric and radial markings, and in polarised light present a distinct "cross." They consist of carbonate of lime for the most part, but inclose portions of gum also. When plunged into stronger solutions of gum these spheres lose their globular arrangement and break up into radial lines, and subsequently into smaller particles. This is Mr. Rainey's fundamental fact; and others entirely analogous have been observed by Harting, Guthrie, and Montgomery, with different substances, and by somewhat different processes. Mr. Rainey was of opinion that these artificial spheres were the exact analogues of the globular masses detected by the microscope in bone, shell, in the testa of crustaceans, as in the tail of the shrimp, for example, and in ossified tendons, and he proceeded to argue that by a purely physical process in which the colloidal environment was concerned, not only bone, but starch granules and even the crystalline lens of the eye were formed. To these fundamental experiments Dr. Ord has himself contributed parallel observations on the disintegration of crystals of uric acid, carbonate and oxalate of lime, murexide, \&c., which, when inclosed in gelatin, glycerine, or glycerine jelly, lose their sharpness of outline and transparency of substance, and progress by degrees towards the spherical form.
Dr. Ord now points out the very important relation held by these obscure molecular processes to the production of spherical and spheroidal concretions of calcareous matter in the renal and urinary organs, and he has sought to establish this relation by two lines of investigation : (I) by microscopic observation of calculi and other urinary deposits obtained under certain morbid conditions; (2) by synthetically obtaining identical forms from the various salts, phosphates, urates, \&c., in the presence of colloids under varying conditions of temperature and hydration.

The substances thus investigated were uric acid, urates, oxalate of lime, phosphates, and carbonates; and the colloids employed were gum, gelatin, albumin, grape-sugar, starch, \&c. The experimental results were throughout compared with the microscopic observations of Thudicum, Beale, and Prout, and a very large proportion of the forms observed in nature were artificially reproduced, thus affording pregnant suggestions as to the varying circumstances which prevailed in their natural production. Many of these comparative observations are of considerable interest. Thus we learn, on p. 55, that the collospheres of uric acid are always very small and homogeneous when deposited in urine, though they are rare; and a "dumb bell" form is still rarer. Both are found in albuminous urine of small density. The experiments with watery solutions of egg-albumin always gave large and brilliant spheres. The conclusion is that the presence of small quantities of urea may retard the formation of the collospheres of uric acid. This supposition is strengthened by the known effect of urea in small quantities in modifying the crystal form of chloride of sodium. Another deduction is of equal moment. Two-thirds of all urinary calculi are composed of, or start from, a nucleus of uric acid. This uric acid would be quite unlikely to cohere in globules without the presence of a colloidal body-the mucus which would undoubtedly be present. "To make calculi of uric acid without colloids would be as hopeless a task as making ropes of sea-sand." This should be remembered in attempting to prescribe a regimen for suspected calculous disease. Whenever the urine is for any length of time purulent and ammoniacal, the formation of calculus is to be looked for. This conclusion is confirmed by a case given in detail by Dr. Ord, in which paralysis led to renal disease, and which he sums up as follows :--" First comes the paralysis leading to retention; retention permits decomposition and the formation of carbonate of ammonia; then come cystitis and the mixture of mucus and albuminous fluid with the triple phosphate and the spherical urates; and so a calculus is formed." Some of the calculi figured by Dr. Bealenotably those of dumb-bell form-were experimentally found to be reproduced by a scarcely suspected substance -oxalate of lime. It was further shown that pre-existing crystals may be resolved into dumb-bell forms in two ways: either by the formation of a dumb-bell within the crystal, or by a disintegration of the crystal and its subsequent conversion in mass into a non-crystalline, homogeneous dumb-bell.

Catching at a suggestion of Rainey's that the peculiar action of the colloid resulted from its viscosity, Dr. Ord conceived that some independent evidence for or against this notion might be afforded by the influence of the apparent, viscosity of the magnetic field. Without 